\section{Lingual Cortical Mandibular Bone Depression: Frequency and Clinical-Radiological Features in a Brazilian Population}

Carlos Fernando de Almeida Barros Mourão ${ }^{1}$, Águida Maria Menezes Aguiar Miranda ${ }^{2}$, Eduardo José da Costa Santos ${ }^{3}$, Fábio Ramôa Pires ${ }^{4}$
'Oral Surgery, Estácio de Sá University, Rio de Janeiro, RJ, Brazil ${ }^{2}$ Stomatology and Oral Surgery, Estácio de Sá University, Rio de Janeiro, RJ, Brazil ${ }^{3}$ Center for Study and Diagnosis in Tomography, Rio de Janeiro, RJ, Brazil ${ }^{4}$ Stomatology and Graduation Program in Dentistry, Estácio de Sá University, RJ, Rio de Janeiro, Brazil

Correspondence: Prof. Dr. Fábio Ramôa Pires, Avenida Alfredo Baltazar da Silveira, 580 cobertura, Recreio dos Bandeirantes, 22790-701 Rio de Janeiro, RJ, Brasil. Tel: +55-21-24978988. e-mail: ramoafop@yahoo.com

Key Words: mandible, depression, Stafne's bone defect, conebeam computed tomography.

\section{Introduction}

Back in 1942, Stafne described a series of 35 asymptomatic radiolucent images close to the angle of the mandible below the mandibular canal. He suggested that their etiology was associated with a congenital or embryonic defect in bone formation leading to mandible hypoplasia in the area (1). This entity, presently known as lingual cortical mandibular bone depression (LCMBD), Stafne's bone defect or salivary gland lingual mandibular bone depression, remains controversial especially with respect to its etiology and development. Only few studies have focused on the frequency and demographic and radiological profile of $L C M B D$ in the worldwide population (2), but there are so far no studies including Brazilian populations. These studies have evaluated LCMBD by conventional radiological techniques or dry mandibles and there are no references to their frequency and pattern of distribution when studied by cone-beam computed tomography (CBCT) scans. The aim of the present study was to present a case series of LCMBD diagnosed by means of three distinct methods to highlight the demographic, imaging and diagnostic features of this entity.

\section{Material and Methods}

Three methods were used in the study. The first one consisted on a retrospective analysis of 3,000 clinical files containing panoramic radiographs retrieved from the
Dental Clinic, Estácio de Sá University, Rio de Janeiro, Brazil, from 2002 to 2010. All radiographs were obtained in the Oral Radiology clinic from the same institution using two radiological equipments (Orthoralix 9200 AEC; Gendex, Des Plaines, IL, US; and Rotograph Plus, Dent-X; Villa Sistemi Medicali, Milan, Italy). They were all obtained as part of the initial dental examination for conventional dental treatment and were consecutively selected and individually reviewed from up to 3,000 radiographs. Clinical files containing panoramic radiographs without adequate quality and preservation, with technical artifacts limiting complete analysis of the mandible, showing superimposed structures (e.g., hyoid bone) or injured for any other reason were excluded from the study. All cases with radiological images compatible with LCMBD were selected and evaluated by at least two of the authors for confirmation of diagnosis.

The second method consisted in a retrospective analysis of 2,421 clinical charts retrieved from the Oral Medicine Clinic, Estácio de Sá University, between September 2002 and December 2010. Data from all patients referred for this clinic for diagnosis of oral and maxillofacial diseases (including both soft-tissue and bone diseases) were reviewed and all cases diagnosed as LCMBD were selected. Radiographs from these patients were also reviewed by two of the authors for diagnosis confirmation.

After selection of the LCMBD cases diagnosed by 
these two first methods, clinical charts of the patients were reviewed for retrieval of clinical and demographic information. Images diagnosed as LCMBD were carefully re-evaluated by two authors for measuring the largest anterior-posterior and upper-lower diameters as well as the distance from the inferior cortical limit of the images and the inferior external cortical surface of the mandible by using a millimeter grade (all measures in $\mathrm{mm}$ ). All radiological analyses were performed in a specific room with a reduced room light.

The third method consisted on a retrospective analysis of consecutive CBCT scans obtained with the same equipment (ICat; Imaging Sciences, Hatfield, PA, USA) at the Center for Study and Diagnosis in Tomography between November 2007 and May 2010. A total of 1,684 CBCT exams performed for regular dental treatment, implant planning, diagnosis of tooth fractures or other dental alterations, or diagnosis of bone diseases located in other areas apart from the posterior mandible, were reviewed and all images diagnosed as LCMBD were selected. Clinical and demographic information were obtained from the patient files and the same distances obtained on the radiographs were obtained on the CBCT scans.

Diagnosis of LCMBD followed the criteria suggested by Philipsen et al. (2) and included: 1) lingual posterior variant - round to ovoid well-defined radiolucent image close to the inferior posterior area of the mandible from primary molar to ramus; 2 ) anterior lingual variant - well-defined radiolucent area superimposed or not to the anterior inferior teeth; 3) lingual variant in the mandible ramus well-defined radiolucent area posterior to the mandible foramina up to the condyle. In cases with available CBCT scans, the images were classified as type I, type II and type III, according to the criteria proposed by Ariji et al. (3).

This was a retrospective study working with data from clinical and radiological records and patients were not examined or interviewed specifically for the study. The Helsinki Declaration's guidelines were followed.

Table 1. Demographic, clinical and radiological data from 20 lingual cortical mandibular bone depressions diagnosed in 18 patients

\begin{tabular}{|c|c|c|c|c|c|c|c|c|c|c|}
\hline Group & Gender & Age (yrs) & Limits & Region & Side & Teeth/region & PBS & Size $^{*}$ & Distance $^{* *}$ & Type (CT) $)^{* * * *}$ \\
\hline \multirow{8}{*}{ OMC } & Male & 19 & WD & Posterior & Right & $45-46$ & Yes & $15 \times 11$ & 4 & 1 \\
\hline & Male & 72 & WD & Posterior & Left & $36-37$ & No & $15 \times 7$ & 9 & NA \\
\hline & \multirow{2}{*}{ Female } & \multirow{2}{*}{37} & ID & Posterior & Left & $35-36$ & No & $22 \times 15$ & 4 & NA \\
\hline & & & ID & Posterior & Right & $44-46$ & No & $23 \times 15$ & 4 & NA \\
\hline & Female & 52 & WD & Anterior & Right & $31-43$ & Yes & $25 \times 15$ & 5 & NA \\
\hline & \multirow{2}{*}{ Male } & \multirow{2}{*}{73} & WD & Posterior & Right & Angle & Yes & $13 \times 8$ & 0 & NA \\
\hline & & & WD & Posterior & Left & Angle & Yes & $10 \times 6$ & 0 & NA \\
\hline & Male & 40 & WD & Posterior & Right & 48 & Yes & $10 \times 6$ & 3 & 11 \\
\hline \multirow{2}{*}{ RPR } & Male & 58 & ID & Posterior & Left & 38 & No & $14 \times 11$ & 2 & NA \\
\hline & Female & 31 & WD & Posterior & Right & 48 & Yes & $30 \times 10$ & 5 & NA \\
\hline \multirow{10}{*}{ СВСТ } & Female & 60 & ID & Posterior & Left & 38 & No & $5 \times 2$ & 3 & 1 \\
\hline & Male & 27 & ID & Posterior & Left & 38 & No & $12 \times 6$ & 2 & 11 \\
\hline & Male & 59 & WD & Posterior & Left & 38 & Yes & $21 \times 6$ & 3 & 11 \\
\hline & Male & 63 & WD & Posterior & Right & 48 & Yes & $14 \times 8$ & 0 & 11 \\
\hline & Male & 52 & WD & Anterior & Right & $42-43$ & Yes & $7 \times 5$ & 16 & 1 \\
\hline & Female & 60 & WD & Posterior & Left & 38 & Yes & $11 \times 7$ & 3 & 1 \\
\hline & Male & 49 & ID & Posterior & Right & $46-47$ & No & $12 \times 5$ & 3 & 1 \\
\hline & Male & 44 & WD & Posterior & Right & 48 & Yes & $11 \times 13$ & 1 & 11 \\
\hline & Male & 70 & WD & Posterior & Left & 38 & No & $4 \times 4$ & 7 & 1 \\
\hline & Male & 61 & WD & Posterior & Left & Angle & Yes & $9 \times 12$ & 11 & 11 \\
\hline
\end{tabular}

OMC: Oral Medicine clinic. RPR: Routine panoramic radiograph. CBCT: Cone bean computed tomography. WD: Well-defined. ID: Ill-defined. PBS: Peripheral bone sclerosis. *: Greatest anterior-posterior $\mathrm{x}$ upper-lower diameters in $\mathrm{mm}$. ${ }^{* *}$ Distance from the lower limit of the defect to the external inferior cortical limit of the mandible in $\mathrm{mm}\left(0=\right.$ superimposed). ${ }^{* * *}$ Type of $\mathrm{CT}$ image according to Ariji et al. (3) (NA = not available). 


\section{Results}

A total of 20 LCMBD cases were diagnosed in 18 patients (two patients presented bilateral LCMBD). From the 3,000 consecutive panoramic radiographs, 2 patients $(0.07 \%)$ presented LCMBD; from the 2,421 patients retrieved from the Oral Medicine clinic, $6(0.25 \%)$ were diagnosed with 8 LCMBD; and from the 1,684 consecutive CBCT scans, 10 LCMBD were encountered (0.59\%). The 18 patients had a mean age of 51.5 years, ranging from 19 to 73 years, and 13 $(72 \%)$ were males. The right and left side of the mandible were affected in 8 cases each and 2 patients presented bilateral lesions (Table 1).

All patients were asymptomatic and the 20 LCMBD were diagnosed in routine exams. Fourteen (70\%) images were classified as well-defined and $6(30 \%)$ as ill-defined radiolucencies. From the 14 well-defined images, 12 were bordered by a peripheral area of bone sclerosis. Eighteen out of the 20 lesions affected the posterior mandible and two affected the anterior mandible. Size of the LCMBD had mean anterior-posterior diameter of $14.2 \mathrm{~mm}$ (ranging from 4 to $30 \mathrm{~mm}$ ), and mean upper-lower diameter of $8.6 \mathrm{~mm}$ (ranging from 2 to $15 \mathrm{~mm}$ ). Analyzing only the patients under 55 years $(n=9)$, the mean anterior-posterior and upper-lower diameters were $16.7 \mathrm{~mm}$ (range 7-30 mm) and $10.1 \mathrm{~mm}$ (range $5-15 \mathrm{~mm}$ ), respectively. For patients older than 55 years of age $(n=9)$ these values were,
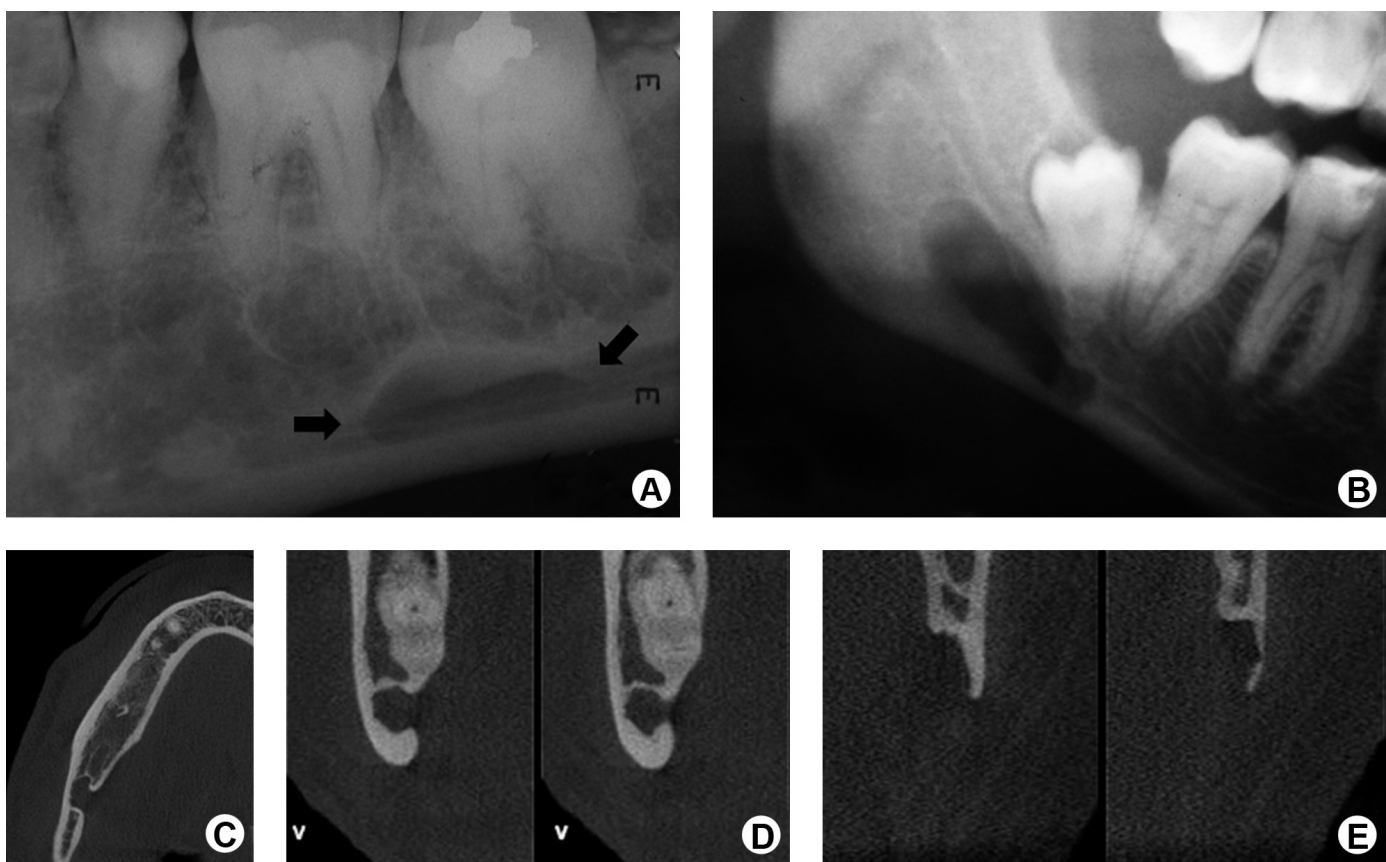

Figure 1. A: Periapical radiograph showing a lingual cortical mandibular bone depression (LCMBD) on the area of the first and second left lower molars (arrows). B: Detail of a panoramic radiograph showing a large LCMBD on the right posterior mandible. C: Cone bean computed tomography (CBCT) axial scan showing the lingual depression. D: type 1. E: type 11 LCMBD according to Ariji et al. (3).
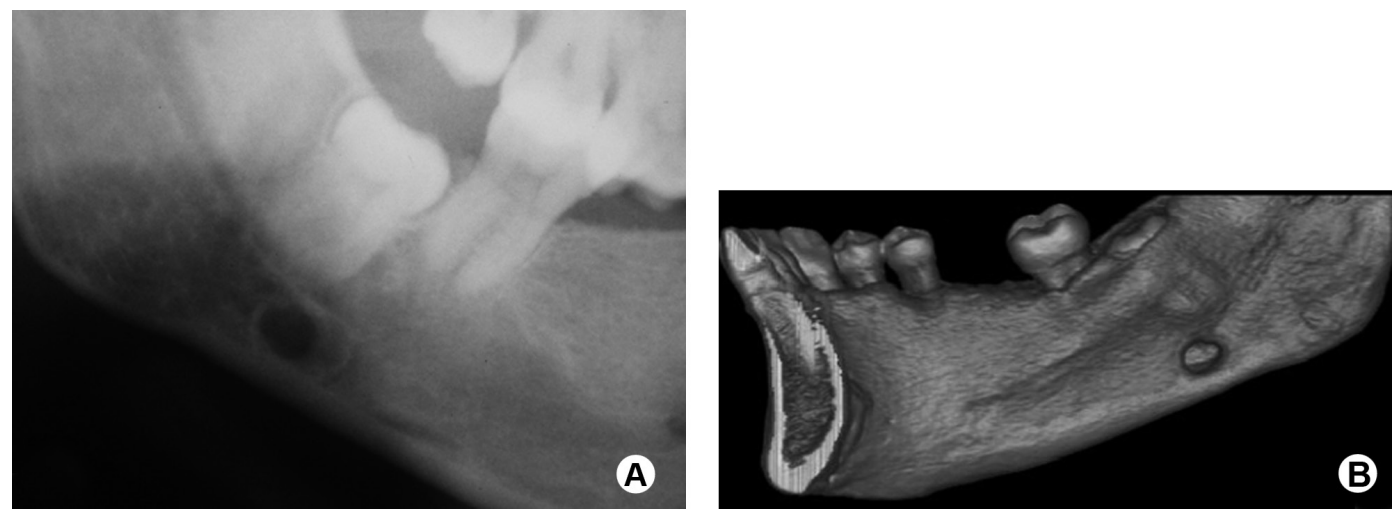

Figure 2. A: LCMBD on the right posterior area of the mandible (detail of a panoramic radiograph). B: Three-dimensional image of the same area in a cone bean computed tomography (CBCT) scan. 
respectively, $11.6 \mathrm{~mm}$ (range $4-21 \mathrm{~mm}$ ) and $7.1 \mathrm{~mm}$ (range 2-12 mm). All LCMBD were located close to the inferior cortical mandible, except for one anterior lesion, far 16 $\mathrm{mm}$ from this limit. Mean distance from the lower limit of the defects to the inferior external cortical mandible limit was $4.3 \mathrm{~mm}$, ranging from 0 to $16 \mathrm{~mm}$; in 3 cases the images were superimposed to this limit (value $=0$ ). In 12 CBCT scans, images were classified as type I $(n=6)$ and type II ( $n=6)$, according to Ariji et al. (3) (Table 1; Fig. 1 and 2). None of the 20 cases included in this analysis was submitted to any surgical approach for diagnosis/treatment.

\section{Discussion}

Etiology of $\mathrm{LCMBD}$ remains controversial. It was initially suggested that this condition could be associated to hypoplasia of the mandible due to incomplete calcification of the Meckel cartilage during ossification (1). Fordyce (4) identified glandular tissue on these defects through surgical intervention, suggesting that they could be induced by a congenital anatomical defect associated to embryonic remnants of the submandibular gland entrapped during mandible ossification. The rarity of these lesions in children, however, does not support this embryonic/congenital theory (5). Trauma on the area, leading to development of solitary bone cysts and radiological defects, as well as vascular pressure from the facial artery to the region were also suggested as etiological factors (2). Harvey and Noble (6) observed active microscopic areas of bone remodeling with osteoblastic activity in the cortical region of these defects, suggesting the existence of persistent bone compression at the lingual surface.

Most recent studies and reports support that the condition is derived from pressure due to hyperplasia, hypertrophy or displacement of the salivary glands towards the adjacent bone surface, leading to bone remodeling in response to the chronic stimuli on the cortical zone (2). Besides its usual location, associated with the submandibular gland, this theory could explain the existence of anterior defects associated with the sublingual glands $(7,8)$ and the defects on the ascending ramus associated to the parotids (9). Salivary gland development begins in the $4^{\text {th }}$ to $12^{\text {th }}$ week of fetal development and mandible ossification usually starts during the $7^{\text {th }}$ week and the fibrous capsule is the last component to be differentiated. In this way, it should not be uncommon to find salivary gland tissue nearby or inside bone, reinforcing this hypothesis. Salivary gland tumors, especially mucoepidermoid carcinomas, arising centrally in the mandible, have been reported in the literature, reinforcing the close relationship of salivary and bone tissues in this area (10). Nevertheless, Campos et al. (11) called attention to the fact that this theory could not explain all images, since some cases are found in the angle of the mandible, in the area of pterygoid muscle insertion, far from the usual submandibular gland location, as exemplified by 3 of the present cases.

Due to the controversial etiology and the radiological variants, several terminologies have been already suggested for this condition, such as embryonic or congenital mandibular defect; developmental defect of the mandible; static or latent bone cyst; Stafne's bone cavity, cyst of defect; submandibular gland inclusion; static bone cavity; lingual mandibular developmental depression of the salivary glands; and lingual posterior mandibular bone concavity, cavity or defect $(2,12-14)$. The three most frequently used are $L C M B D$, Stafne's bone defect and salivary gland lingual mandibular bone depression.

The literature shows a variable prevalence of LCMBD, depending on the applied methods and diagnostic criteria. Studies using panoramic radiograph analysis show prevalence ranging from 0.08 to $0.48 \%(2,13,15-20)$. As expected, studies focusing the observation of the defect in dried mandibles have found higher values, ranging from 0.79 to $1.3 \%(6,21,22)$ (Table 2). Frequency of LCMBD in routine panoramic radiographs in the present study $(0.07 \%)$ was similar to the results of Sisman et al. (20) and slightly lower than the other values reported in the literature, a feature that can be associated with different diagnostic criteria and/or truly geographic and population differences.

Table 2. Prevalence of lingual cortical mandibular bone depressions (LCMBD) reported in the literature

\begin{tabular}{lcccc}
\hline & & & \multicolumn{2}{c}{ LCMBD } \\
\cline { 4 - 6 } Authors & Year & N (total) & $\mathrm{n}$ & $\%$ \\
\hline Studies using radiographs & & & & \\
$\quad$ Lilly et al. (15) & 1965 & 1,287 & 2 & 0.16 \\
Karmiol and Walsh (16) & 1968 & 4,963 & 18 & 0.36 \\
Johnson (17) & 1970 & 2,486 & 10 & 0.40 \\
Oikarinen and Julku (18) & 1974 & 10,000 & 10 & 0.10 \\
Uemura et al. (19) & 1976 & 3,000 & 10 & 0.33 \\
Correll et al. (13) & 1980 & 2,693 & 13 & 0.48 \\
Philipsen et al. (2) & 2002 & 42,600 & 69 & 0.16 \\
Sisman et al. (20) & 2012 & 34,221 & 29 & 0.08 \\
Present study* & 2013 & 3,000 & 2 & 0.07 \\
Studies using dry mandibles & & & & \\
Harvey and Noble (6) & 1968 & 953 & 9 & 0.94 \\
Kay (21) & 1974 & 1,385 & 11 & 0.79 \\
Langlais et al. (22) & 1976 & 469 & 6 & 1.3 \\
\hline
\end{tabular}

"Including only the 3,000 revised panoramic radiographs. 
The methods used in the present study followed strictly the diagnostic criteria from the revision of Philipsen et al. (2), including solely typical images diagnosed after careful review performed by two examiners. It is interesting to notice that the frequency obtained by CBCT scans review, as expected by the characteristics of the images obtained with this technique, was higher than those reported by conventional radiographs. There are no other studies in the literature reporting the frequency of LCMBD on CBCT scans analysis for comparison of these data.

LCMBD predominantly affects adults in the 5 th to 6 th decades of life, with a predilection for men $(2,9,13,14,16,18$ $20,23)$, in accordance with the results of the present study. Previous studies have reported a higher prevalence of the lingual posterior variant (from the angle of the mandible to the first molar) $(1-3,20)$, and this region was affected in 18 out of the reviewed 20 cases. The other two cases affected the anterior lingual region (anterior to premolars) and no case affecting the lingual/vestibular regions of the ascending ramus was found. Philipsen et al. (2) analyzing 42,600 radiographs found 69 cases (65 in the posterior and 4 in the anterior area); Sisman et al. (20), studying 34,221 panoramic radiographs, reported 29 cases, including 28 posterior and 1 anterior defect. Bilateral LCMBD can represent $3 \%$ to $25 \%$ of the cases $(1,2)$, and were found in $11 \%$ of the patients reported in the present study.

The diagnosis of the LCMBD is usually established during routine panoramic radiographic examination, as the defect is almost always asymptomatic $(2,6,23)$. In rare cases it is possible to feel the lingual depression on palpation and in some cases can be associated with buccal expansion of the mandible cortical bone (3). The typical feature is a round to ovoid unilocular radiolucent image, ill-defined or welldefined with a sclerotic border, situated in the posterior area of the mandible, below the mandibular canal and close to the inferior cortical border, ranging from 1.0 to $3.0 \mathrm{~cm}$ in size (2). The cases included in the present series presented similar features; nevertheless, it is important to stress the differences in the dimensions of the images, as well as the variable distance from the cortical area of the mandible. The mean distance from the lower limit of the defects and the lower border of the mandible $(4.3 \mathrm{~mm})$ found in the present study was similar to the mean reported by Correll et al. (13) $(3.3 \mathrm{~mm})$; the same authors described 2 cases with limits superimposed to the lower border of the mandible (15.4\%), similarly to the present findings $(15 \%)$. The same study reported additionally that all their 13 images showed well-defined borders, and 10 presented a sclerotic halo. Fourteen out of the 20 presently reported cases showed well-defined images and 12 also showed a sclerotic border. In contrast to the results of Oikarinen and Julku (18), the findings of the present study showed that younger patients presented larger defects than the older group. Although the low number of cases does not exclude the possibility of bias, these results may suggest that some defects can decrease in size with time.

In clinical practice, when a typical image of the condition is observed in a panoramic radiograph from an asymptomatic patient, it is usually sufficient for diagnosis. However, axial and coronal CT scans highlight the lingual concavity located beneath the milohyoid line and above the lower border of the mandible, characteristic of the condition (20). Additional image techniques (sialography, sialotomographic and magnetic resonance images) can be also useful in individual cases $(2,3,8,23)$. The presence of the lingual concavity is an important finding on differential diagnosis with other conditions that can affect the same region, such as odontogenic cysts and tumors, salivary gland and neurogenic tumors, vascular lesions, benign fibro-osseous lesions, idiopathic bone cavities, central giant cell lesions, multiple myeloma, bone lesions in hyperparathyroidism and Langerhans cell hystiocitosis $(3,19)$. However, although the defect is almost always found on the lingual surface, it can be also found on the buccal surface of the ascending ramus associated with the superficial lobe of the parotid (2). The depth of the bone depression in the lingual posterior variant can be quite variable and Ariji et al. (3) have suggested that the lesions could be classified in: type I (the depression does not reach the buccal cortical), type II (the depression reaches the vestibular cortical, but does not change its contour) and type III (the depression reaches and produces bone expansion of the buccal cortical). In the present study, 12 cases were classified according to these criteria, showing a homogeneous distribution in type I (6 cases) and type II ( 6 cases) images. LCMBD cases affecting the area anterior to the premolars have been reported in the literature and were suggested to be associated with hypertrophy of the sublingual glands $(7,8,24)$. In this region, a careful analysis of the area with both conventional radiographs and CT scans is advisable to rule out the possibility of other bone diseases and to avoid unnecessary surgical interventions $(8,24)$. It is interesting to mention that the anterior defects included in the present series were distinctly situated in the upper-lower axis, suggesting that other factors, apart from the close relationship to glandular tissue, could determine their size and location.

There is no strict indication for a surgical approach on the diagnosis of LCMBD as most cases present with a typical radiological appearance. However, surgery has been occasionally indicated in specific situations where the image features are not sufficient for diagnosis or in atypical presentations. The specimens removed from the area of the defect usually show normal salivary gland tissue 
$(4,20,23)$ or, less commonly, skeletal striated muscle and neural, vascular, adipocytic and lymphoid tissue (2). Few cases have shown presence of chronic sialoadenitis and pleomorphic adenomas in the area $(12,14)$.

LCMBD is a benign condition and there is no indication for any specific treatment. Few cases have shown continuous growing of the defect, pain/discomfort in the affected area or interfered with prosthetic rehabilitation (e.g. dental implants). In these very specific situations, surgical management can be an option, and removal of the tissue from the affected area can induce regression of the defect (12). Nevertheless, clinical and radiological follow-up is advisable before considering any possible intervention, as they usually reveal the asymptomatic and static features of the condition $(2,23)$. Sequelae associated with the LCMBD, such as mandible fracture, are extremely uncommon (25).

In conclusion, the present study showed the clinical and radiological features of 20 LCMBD cases. The defects affected mainly adult males and $90 \%$ of the lesions were located on the posterior mandible as well-defined radiolucent unilocular images. The differences in the mean anterior-posterior and the mean upper-lower diameters of the images suggest that lesions could decrease in size with increasing age of the patients.

\section{Resumo}

0 objetivo deste estudo foi relatar a frequência e os achados clínicoradiográficos dos casos de depressão cortical mandibular lingual diagnosticados em radiografias panorâmicas e em tomografias computadorizadas realizadas pela técnica de feixe cônico consecutivas em uma população brasileira. A metodologia incluiu uma análise retrospectiva de radiografias panorâmicas consecutivas, dos registros dos pacientes da clínica de estomatologia e tomografias computadorizadas consecutivas realizadas pela técnica do feixe cônico. Todos os casos com diagnóstico de depressão cortical mandibular lingual foram selecionados e as informações clínico-radiográficas foram obtidas a partir dos prontuários dos pacientes e da análise dos exames imaginológicos. Um total de 20 casos de depressão cortical mandibular lingual foi diagnosticado em 18 pacientes, incluindo 2 casos em 3.000 radiografias panorâmicas $(0,07 \%)$, 6 em 2.421 pacientes da clínica de Estomatologia (0,25\%) e 10 em 1.684 pacientes do grupo submetido a tomografia computadorizada (0,59\%). Os 18 pacientes mostraram uma média de idade de 51,5 anos e 13 eram do gênero masculino. Dois pacientes apresentaram imagens bilaterais. Quatorze imagens (70\%) foram classificadas como bem definidas; dezoito acometeram a região posterior da mandibula e dois casos acometeram a região anterior da mandibula. 0 tamanho das lesões foi maior em pacientes mais jovens. Em conclusão, existe uma considerável heterogeneidade na expressão radiográfica das imagens e parece haver uma diminuição do tamanho das imagens com o aumento da idade dos pacientes.

\section{Acknowledgements}

The authors wish to thank FAPERJ and CNPq for the financial support to this study.
Dent Assoc 1942;29:1969-1972.

2. Philipsen HP, Takata T, Reichart PA, Sato S, Suei Y. Lingual and buccal mandibular bone depressions: a review based on 583 cases from a world-wide literature survey, including 69 new cases from Japan. Dentomaxillofac Radiol 2002;31:281-290.

3. Ariji E, Fujiwara N, Tabata O, Nakayama E, Kanda S, Shirtsuchi $Y$, et al.. Stafne's bone cavity: classification based on outline and content determined by computed tomography. Oral Surg Oral Med Oral Pathol 1993;76:375-380.

4. Fordyce GL. The probable nature of so called latent hemorrhagic cysts of the mandible. Br Dent J 1956;101:40-42.

5. Hansson LG. Development of a lingual mandibular bone cavity in an 11-years-old boy. Oral Surg Oral Med Oral Pathol 1980;49:376-378.

6. Harvey W, Noble HW. Defects on the lingual surface of the mandible near the angle. Br J Oral Surg 1968;6:75-83.

7. Queiroz LM, Rocha RS, Medeiros KB, Silveira EJ, Lins RD. Anterior bilateral presentation of Stafne defect: an unusual case report. J Oral Maxillofac Surg 2004;62:613-615.

8. Sisman Y, Etöz A0, Mavili E, Sahman H, Tarim Ertas E. Anterior Stafne bone defect mimicking a residual cyst: a case report. Dentomaxillofac Radiol 2010;39:124-126.

9. Barker GR. A radiolucency of the ascending ramus of the mandible associated with invested parotid salivary gland material and analogous with a Stafne bone cavity. Br J Oral Maxillofac Surg 1988;26:81-84.

10. Pires FR, Paes de Almeida O, Lopes MA, Elias da Cruz Perez D, Kowalski LP. Central mucoepidermoid carcinoma of the mandible: report of four cases with long-term follow-up. Int J Oral Maxillofac Surg 2003:32:378-382.

11. Campos P, Panella J, Crusoé-Rebello I, Azevedo R, Pena N, Cunha T. Mandibular ramus-related Stafne's bone cavity. Dentomaxillofac Radiol 2004;33:63-66.

12. Simpson W. A Stafne's mandibular defect containing a pleomorphic adenoma. J Oral Surg 1965;23:553-556.

13. Correll RW, Jensen JL, Rhyne RR. Lingual cortical mandibular defects: a radiographic incidence study. Oral Surg Oral Med Oral Pathol 1980;50:287-291.

14. Grellner TJ, Frost DE, Brannon RB. Lingual mandibular bone defect: report of three cases. J Oral Maxillofac Surg 1990;48:288-296.

15. Lilly GE, Steiner M, Irby WB, Tiecke RW. Oral health evaluation: analysis of radiographic finds. J Am Dent Assoc 1965;71:635-639.

16. Karmiol M, Walsh RF. Incidence of static bone defect of the mandible. Oral Surg Oral Med Oral Pathol 1968;26:225-228.

17. Johnson CC. Analysis of panoramic survey. J Am Dent Assoc 1970;81:151-154.

18. Oikarinen VJ, Julku M. An orthopantomographic study of developmental mandibular bone defects (Stafne's idiopathic bone cavities). Int J Oral Surg 1974;3:71-76.

19. Uemura $S$, Fujishita $M$, Fuchihata $H$. Radiographic interpretation of so-called developmental defect of mandible. Oral Surg Oral Med Oral Pathol 1976;41:120-128.

20. Sisman Y, Miloglu O, Sekerci A, Yilmaz A, Demirtas O, Tokmak T. Radiographic evaluation on prevalence of Stafne bone defect: a study from two centers in Turkey. Dentomaxillofac Radiol 2012;41:152-158.

21. Kay LW. Some anthropologic investigations of interest to oral surgeons. Int J Oral Surg 1974;3:363-379.

22. Langlais $\mathrm{RP}$, Cottone $\mathrm{J}$, Kasle MJ. Anterior and posterior lingual depressions of the mandible. J Oral Surg 1976;34:502-509.

23. Quesada-Gómez C, Valmaseda-Castellón E, Berini-Aytés L, Gay-Escoda C. Stafne bone cavity: a retrospective study of 11 cases. Med Oral Patol Oral Cir Bucal 2006;11:E277-E280.

24. Turkoglu K, Orhan K. Stafne bone cavity in the anterior mandible. J Craniofac Surg 2010;21:1769-1775.

25. Kao YH, Huang IY, Chen CM, Wu CW, Hsu KJ, Chen CM. Late mandibular fracture after third molar extraction in a patient with Stafne bone cavity: a case report. J Oral Maxillofac Surg 2010;68:1698-1700.

\section{References}

1. Stafne EC. Bone cavities situated near the angle of the mandible. J Am 